\title{
Bilateral vocal cord paralysis following stent placement for proximal esophageal stricture
}

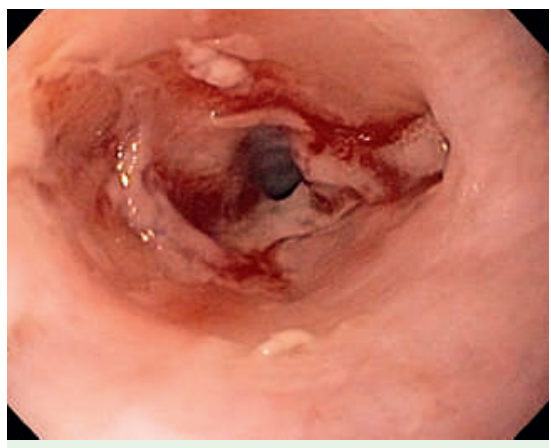

Fig. 1 Malignant-appearing esophageal stricture.

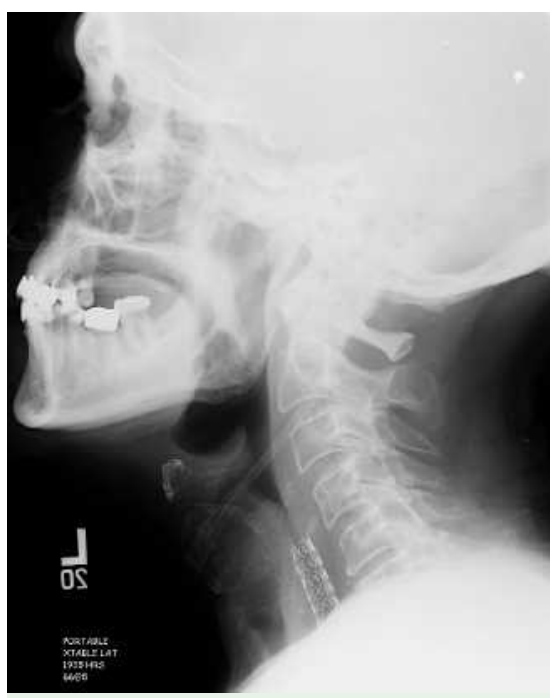

Fig. 2 Plain radiograph of the neck revealing mild subglottic tracheal narrowing and appropriately positioned esophageal stent.

An 83-year-old man with a history of squamous cell cancer of the esophagus presented for endoscopic management of refractory dysphagia. A malignant-appearing esophageal stricture was identi- fied $20 \mathrm{~cm}$ from the incisors ( $\bullet$ Fig. 1). The stricture was dilated with 6- to 8-mm and 8- to 10-mm balloon dilators. An $18 \mathrm{~mm} \times 10 \mathrm{~cm}$ Alimaxx fully covered nitinol stent (Alveolus, Inc., Charlotte, North Carolina, USA) was then placed under fluoroscopic guidance across the stricture.

Several hours after the procedure, the patient developed inspiratory stridor. He presented to the emergency department approximately 12 hours later. Plain radiographs of the neck showed the stent positioned just distal to the upper esophageal sphincter ( $\bullet$ Fig. 2). A CT scan revealed a focal soft tissue prominence between the esophagus and trachea at the level of T1, indicating prior radiation, residual mass, or recent injury ( $\bullet$ Fig. 3 ). There was no evidence of external airway compression. Fiberoptic laryngoscopy demonstrated bilateral vocal cord paralysis. Despite removal of the stent, the patient required a tracheostomy.

The most common causes of bilateral vocal cord paralysis in adults include iatrogenic recurrent laryngeal nerve injury during thyroidectomy or endotracheal intubation, followed by neurologic disorders and malignancy [1]. Additionally, there are reports of laryngeal nerve paralysis secondary to achalasia [2], esophageal foreign bodies [3], and use of an esophageal overtube [4]. In the present case, we presume the cause of injury was recurrent laryngeal nerve compression following placement of the esophageal stent. The delay in presentation to the emergency department may also have resulted in more severe nerve injury as therapeutic decompression was delayed.

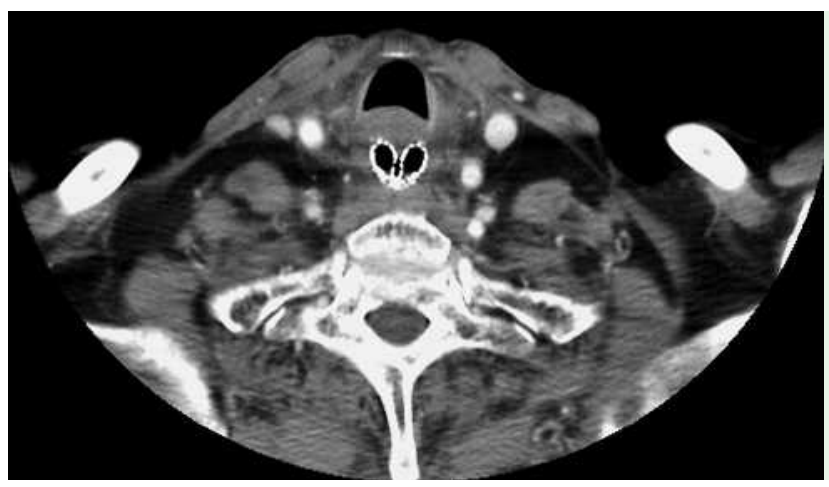

Fig. 3 CT scan demonstrating a centrally collapsed esophageal stent and a soft tissue prominence interposed between the esophagus and trachea at the level of $\mathrm{T} 1$.
Verschuur et al. recently reported their experience with esophageal stents in the proximal esophagus [5]. Twenty-one percent of subjects in their study experienced major complications including aspiration pneumonia, hemorrhage, fistula, and perforation. Stridor was not reported. We would suggest that endoscopists consider recurrent laryngeal nerve injury as a potential complication following proximal esophageal stent placement.

Endoscopy_UCTN_Code_CPL_1AH_2AD

\section{Z. F. Gellad ${ }^{1}$, D. Hampton ${ }^{1}$, C. L. Tebbit ${ }^{2}$,}

\section{Puscas' ${ }^{2}$, D. A. Pavey ${ }^{1}$}

Division of Gastroenterology, Department of Medicine, Duke University Medical Center, Durham, North Carolina, USA

2 Division of Otolaryngology, Head and Neck Surgery, Department of Surgery, Duke University Medical Center, Durham, North Carolina, USA

\section{References}

1 Holinger LD, Holinger PC. Etiology of bilateral abductor vocal cord paralysis: a review of 389 cases. Ann Otol Rhinol Laryngol 1976; 85: $428-436$

2 Chegar BE, Emko P. Bilateral vocal cord paralysis secondary to esophageal compression. Am J Otolaryngol 2004; 25: 361 - 363

3 Virgilis D, Weinberger JM, Fisher D et al. Vocal cord paralysis secondary to impacted esophageal foreign bodies in young children. Pediatrics 2001; 107: 101

4 Holderman WH, Etzkorn KP, Patel SA et al. Endoscopic findings and overtube-related complications associated with esophageal variceal ligation. J Clin Gastroenterol 1995; 21: $91-94$

5 Verschuur EML, Kuipers EJ, Siersema PD. Esophageal stents for malignant strictures close to the upper esophageal sphincter. Gastrointest Endosc 2007; 66: 1082-190

Bibliography

Dol $10.1055 / \mathrm{s}-2007-995773$

Endoscopy 2008; 40: E150

(c) Georg Thieme Verlag KG Stuttgart · New York . ISSN 0013-726X

Corresponding author

\section{Z. F. Gellad, MD, MPH}

Division of Gastroenterology

Duke University Medical Center

Box 3913

Durham

NC 27710

USA

Fax: +1-919-6848857

z.gellad@duke.edu 